\title{
Effect of Oregano and Marjoram Essential Oils on the Physical and Antimicrobial Properties of Chitosan Based Systems
}

\author{
Jana Sedlaříková, ${ }^{1}$ Magda Doležalová, ${ }^{2}$ Pavlína Egner,, Jana Pavlačková, ${ }^{1}$ Jiří Krejčí, \\ Ondřej Rudolf, ${ }^{1}$ and Petra Peer ${ }^{3}$ \\ ${ }^{1}$ Department of Fat, Surfactant and Cosmetics Technology, Faculty of Technology, Tomas Bata University in Zlin, \\ Vavrečkova 275, 76001 Zlín, Czech Republic \\ ${ }^{2}$ Department of Environmental Protection Engineering, Faculty of Technology, Tomas Bata University in Zlín, \\ Vavrečkova 275, 76001 Zlín, Czech Republic \\ ${ }^{3}$ Institute of Hydrodynamics, Academy of Science of the Czech Republic, Pod Pat'ankou 30/5, 16612 Prague 6, Czech Republic
}

Correspondence should be addressed to Jana Sedlaříková; sedlarikova@ft.utb.cz

Received 27 March 2017; Accepted 23 May 2017; Published 20 June 2017

Academic Editor: Nabil Ibrahim

Copyright ( 2017 Jana Sedlař́ková et al. This is an open access article distributed under the Creative Commons Attribution License, which permits unrestricted use, distribution, and reproduction in any medium, provided the original work is properly cited.

\begin{abstract}
The effect of two essential oils (EOs), from Origanum vulgare and Origanum majorana, their structural properties, and concentration on physical and antimicrobial characteristics of chitosan based solutions as well as films was investigated. Results showed that significantly different behaviour was induced by variation in the compositions of given essential oils. Film-forming solutions (FFS) containing oregano oil comprised considerably greater particles in comparison with the marjoram samples. Similarly, structural changes were confirmed by SEM analysis of chitosan films modified with the EOs; the smaller particles of the marjoram oil demonstrated better compatibility with chitosan matrix. However, chitosan films enriched with the oregano oil showed significantly superior antimicrobial activity compared to the marjoram. The dissimilar effects of the two EOs were also observed by water vapour pressure (WVP) measurement; increasing the amount of oregano oil triggered a drop in the WVP of the prepared films, whereas the marjoram oil had a negligible impact in this respect. These results suggest that the structural features of active substances in the EOs play a crucial role in determining the final properties of FFS and biofilm systems.
\end{abstract}

\section{Introduction}

Chitosan is a polysaccharide obtained by deacetylation of chitin, constituting the second most important natural polymer in the world. The main sources of chitin are crustacean shells, such as those of shrimp, crab, and crawfish. Due to its unique properties, such as antimicrobial activity, biocompatibility, biodegradability, and nontoxicity, chitosan is utilized in many sectors including the medical, food, and chemical industry. Chitosan can be applied in the form of solutions and gels; moreover, owing to its excellent filmforming characteristics, it has found application as a material for coatings, types of packaging, and wound dressings $[1,2]$. Active food packaging represents an important utilization extending the shelf-life of foodstuffs and raising their quality
$[3,4]$. Coating can be applied by dipping, brushing, or spraying the food item with a film-forming solution, or the film can be prepared in a separated step and subsequently deposited on the food surface. The properties of standalone films can substantially differ from systems applied directly on food from solution. The standard method for preparing a film entails the solvent-casting technique with subsequent evaporation. The temperature and rate of the evaporation process are key factors affecting the properties of the resultant film [5]. The requisite requirements for ideal edible films comprise low water vapour permeability, high mechanical strength, good adhesion, sufficient antimicrobial activity, optimum biochemical and physicochemical stability, suitable sensory parameters, affordable raw materials, and an inexpensive production process, and they must be safe 
for consumption by humans [6]. Physicochemical properties significantly affect behaviour in moist environments, in addition to influencing the oxygen transport, preventing oil and fat migration, aiding retention of volatile flavours, and improving the practical handling of foodstuffs [7].

The antimicrobial activity of chitosan consists in the interaction between the positively charged amino groups of the chitosan molecule with negatively charged bacterial membranes, leading to cell disruption and death. Several studies have shown that these antimicrobial properties can be significantly diminished if chitosan is prepared in the form of an insoluble film $[2,8]$. For this reason, various active agents have been incorporated into chitosan films to improve their antimicrobial characteristics, such as green tea extract [9], garlic oil, potassium sorbate, and nisin [10].

Amongst other aspects, essential oils (EOs) exhibit interesting biological properties, having long been used as active agents for preserving food products [6]. Essential oils are hydrophobic liquids containing volatile aromatic compounds. EOs are primarily obtained from various parts of plants by steam distillation, although other processes include solvent extraction, fermentation, and expression $[11,12]$. Their antimicrobial activity is strongly dependent on the structure and functional groups present. Terpenoic and phenolic compounds, such as carvacrol and thymol, have proven to be highly efficient in this respect $[2,13]$. Indeed, carvacrol, the main component in oregano, thyme, marjoram, and summer savory oil, has been extensively studied and applied as a flavouring and antimicrobial agent in numerous foodstuffs, such as sweets, chewing gum, and beverages [14]. Besides its antimicrobial activity, barrier and antioxidant properties can be enhanced by incorporating these substances into a polymer matrix $[15,16]$. Furthermore, study has been conducted into combinations of chitosan film with various essential oils, for example, rosemary [17], lemon [3], thyme [18], oregano [8], basil [19], cinnamon, and clove [7] with regard to their effect on antimicrobial, mechanical, and barrier properties. However, only a handful of papers have focused on complex evaluation of filmforming dispersions and the resultant films across a wider range of active substance concentrations. Moreover, although oregano oil has been reported to be a strong and highly active substance in polymer films, precious little information is available on combining chitosan and marjoram oil, which stems from the same Origanum genus.

The aim of the work herein was to identify the dominant components in two EOs of the Origanum species, oregano (Origanum vulgare) and marjoram (Origanum majorana). In addition, comparison was made of their effects on the physical and surface properties of film-forming solutions, and analysis was carried out on the antimicrobial and structural characteristics of the chitosan films prepared.

\section{Materials and Methods}

2.1. Materials. Low-molecular chitosan $(133 \mathrm{kDa}, 87 \%$ deacetylated) was purchased from Sigma-Aldrich (CZ). The essential oils of oregano (Origanum vulgare, Romania) and marjoram (Origanum majorana, Egypt) were provided by Nobilis
Tilia s.r.o. (CZ). Microorganisms (Escherichia coli CCM 3954, Salmonella enterica subsp. Enterica ser. Typhimurium CCM 7205, Staphylococcus aureus CCM 3953, Bacillus cereus CCM 2010, Candida albicans CCM 8215, and Aspergillus niger CCM 8155) were obtained from the Czech Collection of Microorganisms (CCM, Czech Republic). The bacterial cultures were grown on Mueller Hinton agar (HiMedia Laboratories, India) at $37^{\circ} \mathrm{C}$ (24 hours), whereas the fungal cultures were grown on Sabouraud agar (HiMedia Laboratories, India) at $20^{\circ} \mathrm{C} \mathrm{(72}$ hours).

2.2. Preparation of Films. The chitosan solution was prepared with $1 \% \mathrm{w} / \mathrm{v}$ chitosan in $1 \% \mathrm{v} / \mathrm{v}$ acetic acid by continuous stirring at room temperature for 24 hours. The solution was then filtrated through a glass filter ( $\mathrm{P} 40$ porosity) to remove undissolved particles and impurities. Afterwards, a mixture of Tween 80 emulsifier (20\% wt.) and essential oil (80\%wt.) was prepared (EE) and added to the polymer solution to obtain final EE concentrations of $0.5,1,2,3,4$, and $5 \%$ (w/w). The dispersion was premixed on a Vortex V-1 Plus device (Biosan, Latvia) for 1 minute and then homogenized with Ultra Turrax IKA ${ }^{\circledR}$ T-25 (IKA, Germany) at 15,600 rpm for 5 minutes.

The chitosan/Tween 80/essential oil solutions $(25 \mathrm{ml})$ were cast on sterile Petri dishes $(90 \mathrm{~mm}$ diameter) and allowed to dry at $35^{\circ} \mathrm{C}$ in an air circulated oven. The dried films were stored at $25^{\circ} \mathrm{C}$ and $60 \%$ relative humidity prior to testing.

Samples were designed as $\mathrm{CH}$ for chitosan without any essential oil, $\mathrm{CH}-\mathrm{O} 0.5$ to 5 for chitosan film with EE (containing oregano oil) in the concentrations 0.5 to $5 \%$ wt., and $\mathrm{CH}-\mathrm{M} 0.5$ to 5 for chitosan with EE (containing marjoram oil) in the concentrations 0.5 to $5 \%$ wt.

2.3. Gas Chromatography Analysis of Essential Oils. The essential oils were examined on a DANI GC Master Fast Gas Chromatograph (Italy) equipped with a Zebron ${ }^{\mathrm{TM}}$ ZB-5MS capillary column (30 m length, $0.25 \mathrm{~mm}$ internal diameter, and $0.5 \mu \mathrm{m}$ film thickness) and flame ionization detector (FID). The carrier gas was nitrogen at a flow rate of $1 \mathrm{ml} / \mathrm{min}$. Column temperature was initially set to $50^{\circ} \mathrm{C}$ and then gradually increased to $120^{\circ} \mathrm{C}$ at stages of $4^{\circ} \mathrm{C} / \mathrm{min}$, after which it was raised to $230^{\circ} \mathrm{C}$ at $15^{\circ} \mathrm{C} / \mathrm{min}$ and left at this level for $15 \mathrm{~min}$. The injection port was heated and maintained at $200^{\circ} \mathrm{C}$. The detector temperature equalled $270^{\circ} \mathrm{C}$. The volume of $1 \mu \mathrm{l}$ of diluted samples of the essential oils in methanol was manually injected using a split ratio of $1: 25$.

2.4. Gas Chromatography-Mass Spectrometry Analysis of Essential Oils. GC-MS analysis of the essential oils was performed on a Shimadzu QP-2010 instrument (Japan). The gas chromatograph was equipped with an Equity ${ }^{\circledR}$ Equity-1 capillary column (30 m length, $0.32 \mathrm{~mm}$ internal diameter, and $1.0 \mu \mathrm{m}$ film thickness). The carrier gas was helium at a flow rate of $2.66 \mathrm{ml} / \mathrm{min}$. Column temperature was initially set to $40^{\circ} \mathrm{C}$ for $10 \mathrm{~min}$ and then gradually increased to $250^{\circ} \mathrm{C}$ at stages of $20^{\circ} \mathrm{C} / \mathrm{min}$ and left at this level for $24.5 \mathrm{~min}$. The injection port was heated and maintained at $250^{\circ} \mathrm{C}$. The volume of $1 \mu \mathrm{l}$ of diluted samples of the essential oils in 
ethyl acetate was automatically injected using a split ratio of $1: 100$. The operating parameters for the mass spectrometer comprised an ion-source temperature of $200^{\circ} \mathrm{C}$, an interface temperature of $250^{\circ} \mathrm{C}$, and ionization energy of $70 \mathrm{eV}$.

\subsection{Characterization of Film-Forming Solutions (FFS)}

2.5.1. Particle Size Measurement and Zeta Potential. The particle size and zeta potential of film-forming solutions (FFS) were measured using a Zetasizer Nano ZS device (Malvern Instruments, Ltd., UK). The samples were diluted by distilled filtrated water via a VWR ${ }^{\circledR}$ syringe filter of $0.2 \mu \mathrm{m}$. The size measurement was performed by laser diffractometry at a $90^{\circ}$ scattering angle, the refractive index being 1.33 and absorption equalling 0.001 . Zeta potential was gauged using folded capillary cells (Malvern Instruments, UK) in automatic mode in adherence with the Smoluchowski model. All measurements were performed at $25 \pm 1^{\circ} \mathrm{C}$ in triplicate.

2.5.2. Surface Tension. The surface tension of the filmforming solutions was measured on an EasyDyne tensiometer $\mathrm{K} 20$ (Krüss $\mathrm{GmbH}$, Germany) at $25^{\circ} \mathrm{C} \pm 1^{\circ} \mathrm{C}$ following the Wilhelmy plate method. The result was an average of five measurements by the instrument.

2.5.3. $\mathrm{pH}$ Measurement. The $\mathrm{pH}$ of the film-forming solutions was gauged with a Eutech spear $\mathrm{pH}$ meter (USA) at $25^{\circ} \mathrm{C}$. All measurements were performed in triplicate.

2.6. Measurement of Film Thickness. The thickness of the prepared chitosan films was determined on a digital micrometer (Schut, Germany) at an accuracy of $\pm 0.006 \mathrm{~mm}$. An average of ten measurements was obtained from various random points on each sample.

2.7. Determination of Moisture Content (MC). Moisture content was analysed by drying portions of the film(s) in an oven at $105^{\circ} \mathrm{C}$ until constant weight was obtained (dry sample weight). The percentage of moisture content was calculated according to (1), where $M_{0}$ is the initial sample weight and $M_{d}$ is the dried sample weight:

$$
\operatorname{MC}(\%)=\left(\frac{M_{0}-M_{d}}{M_{0}}\right) \times 100 \text {. }
$$

2.8. Film Solubility (S) in Water. The solubility of the films was determined using a modified method based upon that devised by [18]. Pieces of film measuring $1 \times 1.5 \mathrm{~cm}^{2}$ were dried in an oven at $105^{\circ} \mathrm{C}$ to the point of constant weight to acquire the initial dry weight $\left(M_{i}\right)$. Then, the samples were placed in a glass beaker containing $50 \mathrm{ml}$ of distilled water and gently agitated for $24 \mathrm{~h}$ at $25^{\circ} \mathrm{C}$. After this time, the remaining film pieces were rinsed with distilled water and dried in an oven at $105^{\circ} \mathrm{C}$ until constant weight was recorded in order to obtain the final dry weight $\left(M_{f}\right)$. All measurements were performed in triplicate and the resulting solubility was expressed according to

$$
S(\%)=\left(\frac{M_{i}-M_{f}}{M_{i}}\right) \times 100 .
$$

2.9. Water Vapour Permeability (WVP). The degree of water vapour permeability was discerned in adherence with standard defined under ASTM E 96-95 [20]. The samples were placed at the open mouth of a test dish containing distilled water ( $100 \%$ relative humidity) and put into a desiccator with silica gel ( $0 \%$ relative humidity). The test dish was periodically weighed (every 2 hours over the duration of 10 hours). Weight loss as recorded for the test dish was plotted as a function of time. The slope obtained by linear regression was used to calculate the water vapour transmission rate (WVT) in $\mathrm{g} \cdot \mathrm{h}^{-1} \cdot \mathrm{m}^{-2}$ according to

$$
\mathrm{WVT}=\frac{(m / t)}{A},
$$

where $m / t$ is weight loss versus time $\left(g \cdot h^{-1}\right)$ and $A$ is the test area in $\mathrm{m}^{2}$ (the mouth area of the test dish).

Water vapour permeability (WVP) in $\mathrm{g} \cdot \mathrm{h}^{-1} \cdot \mathrm{m}^{-2}$ was then calculated as follows:

$$
\mathrm{WVP}=\frac{\mathrm{WVT}}{\Delta p}=\frac{\mathrm{WVT}}{S\left(R_{1}-R_{2}\right)},
$$

where $\Delta p$ is difference in water vapour pressure $(\mathrm{Pa}), S$ is the saturation pressure of vapour at the tested temperature, $R_{1}$ is relative humidity in the test dish expressed as a fraction, and $R_{2}$ is relative humidity at the vapour sink expressed as a fraction.

2.10. SEM Analysis. Characterization of the surfaces and cross sections of the films was evaluated by a Vega 3 high resolution scanning electron microscope (Tescan, Czech Republic). Prior to imaging, the films were sputtered with a conductive coating layer.

2.11. Antimicrobial Activity. The antimicrobial activity of essential oils and chitosan films were tested against selected bacteria, yeasts, and moulds using the agar disc diffusion method. Sterile paper discs (diam. $6 \mathrm{~mm}$, Whatman, UK) were loaded with $10 \mu \mathrm{l}$ of pure essential oils. Discs $(9 \mathrm{~mm}$ in diameter) from the chitosan films were cut with a circular knife. Both disc types were then placed on agar plates previously inoculated with $1 \mathrm{ml}$ of $0.5 \mathrm{McF}$ turbid suspension of bacteria and yeasts in sterile saline solution. Micromycetes grown on Sabouraud agar were overlaid with $0.1 \%$ Tween 80 in sterile saline solution. Prepared suspension was then diluted to range $0.09-0.3$ measured by spectrophotometer at $530 \mathrm{~nm}$. The plates were then incubated under appropriate conditions and after cultivation the diameters of inhibition zones around the discs were measured with a calliper. Antimicrobial activity was checked on the 3rd and 8th days after drying the films, with all tests being carried out in triplicate.

2.12. Statistical Analysis. All measurements were carried out at least in triplicate and the results are expressed as mean \pm standard deviation. One-way analysis of variance (ANOVA) was applied to analyse the experimental data, using Statistica software (version 10, StatSoft, Inc., USA), at the significance level of $P<0.05$. 
TABLE 1: Composition of the oregano and marjoram essential oils.

\begin{tabular}{|c|c|c|c|c|c|}
\hline \multirow{2}{*}{ Component } & \multicolumn{2}{|c|}{ Oregano oil } & \multirow{2}{*}{ Component } & \multicolumn{2}{|c|}{ Marjoram oil } \\
\hline & Rt [min] & Area [\%] & & Rt [min] & Area [\%] \\
\hline Thujene & 13.77 & 1 & Thujene & 13.77 & 0.4 \\
\hline$\alpha$-Pinene & 13.89 & 0.5 & $\alpha$-Pinene & 13.89 & 0.5 \\
\hline Camphene & 14.08 & 0.2 & Sabinene & 14.40 & 6 \\
\hline$\beta$-Pinene & 14.47 & 0.2 & $\beta$-Pinene & 14.47 & 0.4 \\
\hline$\beta$-Myrcene & 14.59 & 1 & $\gamma$-Myrcene & 14.60 & 2 \\
\hline$\alpha$-Terpinene & 14.94 & 0.3 & Phellandrene & 14.79 & 0.3 \\
\hline p-Cymene & 14.97 & 8.5 & $\alpha$-Terpinene & 14.94 & 6 \\
\hline Limonene & 15.09 & 0.5 & p-Cymene & 14.97 & 2 \\
\hline$\gamma$-Terpinene & 15.39 & 6.4 & Limonene & 15.09 & 4 \\
\hline trans-Sabinene-hydrate & 15.45 & 0.4 & $\gamma$-Terpinene & 15.39 & 13 \\
\hline Linalool & 15.71 & 0.6 & trans-Sabinene-hydrate & 15.45 & 4 \\
\hline Borneol & 16.41 & 0.6 & Terpinolene & 15.71 & 4 \\
\hline Terpinene-4-ol & 16.50 & 0.6 & cis-Sabinene-hydrate & 15.76 & 16 \\
\hline$\alpha$-Terpineol & 16.59 & 0.2 & 2-Cyclohexen-1-ol & $15.99-16.14$ & 3 \\
\hline Thymol & 17.28 & 2 & Terpinen-4-ol & 16.50 & 31 \\
\hline Carvacrol & 17.36 & 75 & $\alpha$-Terpineol & 16.58 & 3 \\
\hline \multirow[t]{3}{*}{ Caryophyllene } & 18.54 & 2 & trans/cis-p-Menth-1-en-3-ol & 16.73 & 0.4 \\
\hline & & & Linalyl-acetate $=$ linalool-acetate & 17.05 & 2 \\
\hline & & & Caryophyllene & 18.54 & 2 \\
\hline Total (\%) & & 100 & & & 100 \\
\hline
\end{tabular}

\section{Results and Discussion}

3.1. Gas Chromatography Analysis of Essential Oils. In order to obtain data on the primary active substances influencing the behaviour of the oils in the chitosan matrix, the compositions of the essential oils (marjoram and oregano) applied were analysed by gas chromatography (GC) and gas chromatography-mass spectrometry (GC-MS). GC analysis proved the presence of the following: the main constituents in the oregano oil were carvacrol (58\%), p-cymene $(9.9 \%)$, myrcene (3\%), and thymol (1.8\%); analysis of the marjoram oil revealed the foremost contents to be terpinen-4-ol (23.5\%), $\alpha$-terpinene (9.6\%), and sabinene (8.5\%) (outcomes from said GC analysis are not included in Table 1).

Results gained through the GC-MS method predominantly confirmed the aforementioned findings and supplemented the GC analysis. As can be seen in Table 1, oregano oil was characterized by its dominant active substance, carvacrol (75\%). This is a phenolic compound frequently found in oregano and thyme oil that is also a food additive known to be safe for decades. Carvacrol (Figure 1(a)) has been proven to possess antioxidant and antimicrobial properties against a wide range of microorganisms $[15,16]$. Other compounds detected in the oregano oil included $p$-cymene $(8.5 \%)$ and $\gamma$ terpinene (6.4\%). Surprisingly, thymol (Figure 1(b)), another effective phenolic biocide, herein was seen to constitute just $2 \%$, which is a significantly lower figure than reported in other studies that stated it comprised the main substance [21]. What is clear from this is that the final chemical composition can significantly differ depending on the combination of the locality, climatic conditions, and season in which the plants are gathered.

During analysis of the marjoram oil, an alcohol terpinen4-ol (Figure 1(c)) was found to be the primary constituent (31\%). Amongst others, cis-sabinene hydrate (16\%), $\gamma$-terpinene (13\%), $\alpha$-terpinene (6\%), and sabinene (6\%) were detected. Origanum species generally contain two types of chemical compounds: aromatic monoterpenes (such as carvacrol, thymol, and p-cymene) and thujanes (e.g., sabinene and sabinene hydrate) (Daferera and others 2000). Based on the results of this study, the oregano oil utilized herein could be classified within the first group, whereas the marjoram essential oil would fall within the other.

The degree of certainty for such identification ranges between $83 \%$ and $96 \%$ for all the components analysed. Some of the characteristic structures are depicted in Figure 1.

With regard to the results of the antimicrobial tests, it can be concluded that the combination of oregano oil components (predominantly monoterpenoid phenolic carvacrol) incorporated in the chitosan based system evidently induced a heightened activity against all the tested microorganisms. However, the marjoram samples manifested small particles that were trapped in the chitosan matrix, which exhibited a negligible antimicrobial effect.

3.2. Particle Size and Zeta Potential of FFS. The size and surface charge of particles not only exert a considerable impact on any eventual physicochemical properties, but also 
<smiles>Cc1ccc(C(C)C)cc1O</smiles>

(a)

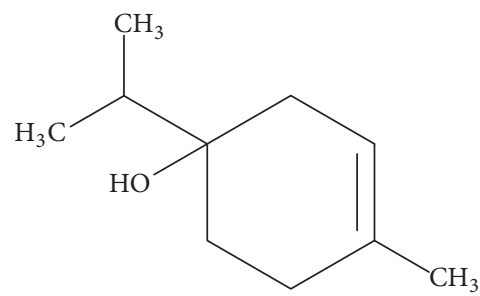

(c)<smiles>Cc1ccc(C(C)C)c(O)c1</smiles>

(b)

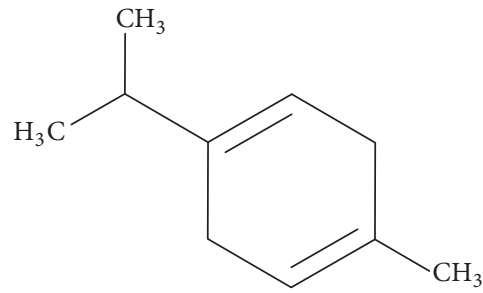

(d)

FIGURE 1: Chemical structures of (a) carvacrol, (b) thymol, (c) terpinen-4-ol, and (d) $\gamma$ terpinene, that is, the active constituents of the oregano and marjoram essential oils.

TABle 2: Particle size and zeta potential of the oregano and marjoram chitosan based film-forming solutions.

\begin{tabular}{|c|c|c|c|c|}
\hline \multirow{2}{*}{ EE concentration (\% wt.) } & \multicolumn{2}{|c|}{ Particle size $(\mu \mathrm{m})$} & \multicolumn{2}{|c|}{ Zeta potential $(\mathrm{mV})$} \\
\hline & $\mathrm{CH}-\mathrm{O}$ & CH-M & $\mathrm{CH}-\mathrm{O}$ & CH-M \\
\hline 0.5 & $4.96 \pm 0.14^{\mathrm{a}}$ & $1.41 \pm 0.04^{\mathrm{a}}$ & $46.53 \pm 2.33^{\mathrm{ac}}$ & $58.83 \pm 2.02^{\mathrm{a}}$ \\
\hline 1 & $4.55 \pm 0.19^{\mathrm{a}}$ & $1.31 \pm 0.03^{\mathrm{a}}$ & $50.13 \pm 1.69^{\mathrm{a}}$ & $34.73 \pm 1.25^{\mathrm{bd}}$ \\
\hline 2 & $1.55 \pm 0.09^{\mathrm{b}}$ & $0.42 \pm 0.02^{\mathrm{b}}$ & $30.93 \pm 0.72^{b}$ & $39.87 \pm 0.91^{\mathrm{c}}$ \\
\hline 3 & $1.08 \pm 0.05^{\mathrm{c}}$ & $0.18 \pm 0.01^{\mathrm{c}}$ & $33.20 \pm 1.48^{\mathrm{b}}$ & $34.37 \pm 0.80^{\mathrm{b}}$ \\
\hline 4 & $0.89 \pm 0.01^{\mathrm{d}}$ & $0.09 \pm 0.00^{\mathrm{d}}$ & $33.97 \pm 3.45^{\mathrm{b}}$ & $38.70 \pm 2.25^{\mathrm{cd}}$ \\
\hline 5 & $0.68 \pm 0.02^{\mathrm{e}}$ & $0.07 \pm 0.00^{\mathrm{e}}$ & $42.60 \pm 2.74^{\mathrm{c}}$ & $39.83 \pm 3.59^{\mathrm{cd}}$ \\
\hline
\end{tabular}

Values are expressed as mean \pm standard deviation. Different letters in the same column indicate significant differences $(P<0.05)$.

alter the appearance, texture, and stability of the system [22]. Herein, the particle size of pure chitosan in acetic acid solution was measured by the dynamic light scattering technique, although, with regard to the characteristics of the polymer solutions, it was only possible to estimate an average value of about $4 \mu \mathrm{m}$, a figure which closely resembles particles of oregano samples containing the lowest concentrations of EE (0.5 and $1 \%$ wt.). Such large particles can be expected in systems where the polymer is highly soluble in the given solvent (aqueous acetic acid solution in this case), thereby favouring polymer chain-solvent interaction, resulting in expansion of the polymer chains [23]. Table 2 compares the size of particles in the film-forming solution with the oregano and marjoram essential oils. Increasing the concentration of EE brought about a decrease in the diameter of the particle size measured, and an evident drop $(P<0.05)$ was observed at $2 \%$ wt. of the essential oil in both (oregano and marjoram) systems. The values for particle size in the $\mathrm{CH}-\mathrm{O}$ and $\mathrm{CH}-$ M samples diminished by $86.3 \%$ and $95.04 \%$, respectively, in comparison with the control. This trend could be ascribed to the strong stabilization activity of the emulsifier used, that is, nonionic Tween 80, regardless of EO type. Contrasting results have been obtained by other authors [14, 22], where particle diameter increased alongside higher content of the active substance (basil and/or thyme oil and carvacrol, respectively).

Another finding was that the FFS with oregano oil contained considerably larger particles than the marjoram solution. At $5 \%$ wt. EE, particle size equalled $0.68 \mu \mathrm{m}$ for oregano, whereas the $\mathrm{CH}-\mathrm{M} 5$ solution included particles one order lower in size. It is known that each oil system has a required HLB (hydrophilic-lipophilic balance) value, and in this case the Tween 80 emulsifier ensured a higher degree of dispersion in the chitosan-marjoram FFS. Following tensiometric measurement, wherein a lower surface tension for the marjoram-emulsifier combination was ascertained, it was confirmed that this system possessed greater surface active properties. However, the presence of smaller particles proved negatively when tested against selected microorganisms. An explanation for this could lie in the small particles of the marjoram essential oil becoming more fixed in the chitosan matrix, thereby resulting in lesser diffusion from the sample to the testing medium.

The effect of EE addition on the values of $\zeta$-potential of film-forming solutions is also shown in Table 2. $\zeta$-potential of chitosan solution (with no EE modification) showed a high positive value of $+58.7 \mathrm{mV}$, which is in accordance 
TABLE 3: $\mathrm{pH}$ values of film forming solutions with various degrees of EE concentrations.

\begin{tabular}{lcc}
\hline EE concentration (\%wt.) & \multicolumn{2}{c}{$\mathrm{pH}$} \\
\hline 0.5 & $3.47 \pm 0.30^{\mathrm{a}}$ & $\mathrm{CH}-\mathrm{M}$ \\
1 & $3.40 \pm 0.37^{\mathrm{b}}$ & $3.51 \pm 0.35^{\mathrm{ac}}$ \\
2 & $3.39 \pm 0.46^{\mathrm{ab}}$ & $3.46 \pm 0.30^{\mathrm{b}}$ \\
3 & $3.38 \pm 0.42^{\mathrm{b}}$ & $3.48 \pm 0.38^{\mathrm{b}}$ \\
4 & $3.38 \pm 0.31^{\mathrm{b}}$ & $3.62 \pm 0.41^{\mathrm{a}}$ \\
5 & $3.63 \pm 0.39^{\mathrm{c}}$ & $3.54 \pm 0.40^{\mathrm{bc}}$ \\
\hline
\end{tabular}

Values are expressed as mean \pm standard deviation. Different letters in the same column indicate significant differences $(P<0.05)$.

with the fact that, at the given $\mathrm{pH}$ of chitosan solution (4.02), the amino groups are positively charged. This value is almost consistent with $\zeta$-potential of CH-M $0.5(58.83 \mathrm{mV})$. The increasing EE content in the samples resulted in the decreasing trend in $\zeta$-potential values with a minimum at $2 \%$ wt. of oregano $(+30.93 \mathrm{mV})$ and $3 \%$ wt. of marjoram oil $(+34.37 \mathrm{mV})$. The reduction of $\zeta$-potential can be attributed to the fact that EO: Tween 80 dispersion without chitosan exhibited negative values, that is, $-30.6 \mathrm{mV}$ for oregano and $-34.2 \mathrm{mV}$ in case of marjoram essential oil. Similar results were obtained in the work of Bonilla et al. [22], who investigated the effect of basil and thyme essential oils on properties of chitosan based films. The presence of negative potential is related to adsorption of negative ions on the oil droplets containing dissociable substances. Combination of chitosan with these essential oils is followed by the increase in the particles surface charge to positive values when compared to EE dispersion. Further EE additions (4 and 5\% wt.) into polymer solution induced a slight increment of potential, which could be caused by the worse homogeneity of solutions at higher content of active substances. However, all the tested samples reveal relatively high positive values of zeta potential indicating a good dispersion stability of the systems and chitosan adsorption at the particle interface.

3.3. Surface Tension. The surface tension of film-forming solutions containing the essential oils was measured to evaluate the effect of particle size on the surface properties of both systems. Based on particle size measurements, a significant drop in surface tension values could be presumed in both dispersions containing approximately $2 \%$ wt. EE mixture. The surface tension of chitosan solution (without the EE addition) was $41.1 \mathrm{mN} \cdot \mathrm{m}^{-1}$ and no significant change arose through oregano modification, since the subsequent figures fluctuated around $41.2 \mathrm{mN} \cdot \mathrm{m}^{-1}$. A more substantial decrease $(P<0.05)$ in surface tension was reported between control and the $\mathrm{CH}$ $\mathrm{M}$ samples. The rise in EE concentration caused a gradual drop in values to $33.2 \mathrm{mN} \cdot \mathrm{m}^{-1}$. However, as demonstrated for the oregano oil, no notable jump was exhibited that would otherwise indicate a micellization process.

3.4. $p H$ of the Film-Forming Solutions. Evaluating the physical properties of the film-forming chitosan solutions involved gauging their $\mathrm{pH}$ levels (Table 3). The $\mathrm{pH}$ value of 4.02 for the chitosan control FFS was close to the value of 3.99 obtained by Elhefian et al. [24], who studied the behaviour of chitosan solutions in acetic acid. Adding the essential oils induced a drop in $\mathrm{pH}(P<0.05)$ in all the tested samples when compared to the control FFS. This could be explained by weak interactions occurring between the chitosan and essential oils. In the case of the oregano solutions, a moderate decrease in $\mathrm{pH}$ was observed in parallel with increased EO concentration; the exception to this was the $\mathrm{CH}-\mathrm{O} 5$ sample, for which the $\mathrm{pH}$ value rose to 3.63. Similarly, in the marjoram samples, after an initial drop, a repeated increment in $\mathrm{pH}$ values followed.

3.5. Physical Properties of the Films. The prepared chitosan films were observed visually prior to further measurement taking place. The chitosan control films were transparent, smooth, and compact, lacking any visible pores and/or deformities. They were also easily peeled off the surface of a Petri dish. Supplementing them with an increasing amount of EE meant the films became opaque and yellowish. The samples with the highest concentrations of EE (4 and 5\% wt.) were nonuniform in appearance with an oily surface, and it was difficult to remove them from the dish.

Physical properties, such as the thickness $(T)$, water vapour permeability (WVP), solubility $(S)$, and moisture content (MC), of the prepared chitosan films are summarized in Tables 4 and 5. It is clear that incorporating the essential oils resulted in significant $(P<0.05)$ increase in film thicknesses, varying between 49.7 and $173.2 \mu \mathrm{m}$ for the $\mathrm{CH}$ $\mathrm{O}$ films. Thinner films were obtained with the marjoram EO, for which the measured thickness ranged between 42.2 and $133.1 \mu \mathrm{m}$. These results were in accordance with particle size measurement of the FFS and the SEM analysis conducted, wherein lesser diameters for the particles were observed in the marjoram systems.

Water vapour permeability indicates the duration of water vapour transmission through the unit area of a flat material induced by the difference in unit vapour pressure between two surfaces, under specified conditions (temperature, humidity) [1]. It ranks as a crucial parameter in applications where the presence of oxygen can result in shortening the shelf-life and reducing the quality of a product. The findings in Table 4 show that adding the oregano essential oil led to decreased WVP values, compared to the control sample of chitosan film $\left(16.51 \cdot 10^{-3} \mathrm{~g} \cdot \mathrm{Pa}^{-1} \cdot \mathrm{h}^{-1} \cdot \mathrm{m}^{-2}\right)$, with a substantial drop happening at $2 \%$ wt. (to $8.95 \mathrm{~g} \cdot \mathrm{Pa}^{-1} \cdot \mathrm{h}^{-1} \cdot \mathrm{m}^{-2}$ ), potentially a consequence of a more hydrophobic structure being produced due to the carvacrol content in the oregano oil. A decrease in water vapour permeability was also obtained by López-Mata et al. [15], who tested samples of chitosan with carvacrol from 0.5 to $1.5 \% \mathrm{v} / \mathrm{v}$. In the study of Fabra et al. [23], diminished water vapour transmission rates were also observed in nanolaminated multilayer films containing carvacrol and zein nanocapsules. Different data were found in a study by Torrieri et al. [25], who detected a rise in the water vapour transmission rate alongside increase in the amount of rosemary essential oil in chitosan films, despite a presumed boost in the hydrophobic nature of the polymer matrix due to a partial presence of lipids. Other authors [26] reported 
TABLE 4: Physical properties of chitosan films with the oregano essential oil.

\begin{tabular}{lcccc}
\hline Sample & $T(\mu \mathrm{m})$ & WVP $\left(10^{-3} \mathrm{~g} / \mathrm{Pa} \cdot \mathrm{h} \cdot \mathrm{m}^{2}\right)$ & MC $(\%)$ & $S(\%)$ \\
\hline $\mathrm{CH}$ & $49.7 \pm 7.6^{\mathrm{a}}$ & $16.51 \pm 0.96^{\mathrm{a}}$ & $20.93 \pm 0.56^{\mathrm{a}}$ & $22.25 \pm 0.31^{\mathrm{a}}$ \\
$\mathrm{CH}-\mathrm{O} 0.5$ & $49.5 \pm 6.9^{\mathrm{a}}$ & $14.04 \pm 1.02^{\mathrm{a}}$ & $19.61 \pm 0.80^{\mathrm{a}}$ & $19.42 \pm 0.27^{\mathrm{b}}$ \\
$\mathrm{CH}-\mathrm{O} 1$ & $69.8 \pm 7.5^{\mathrm{b}}$ & $12.65 \pm 0.87^{\mathrm{a}}$ & $14.68 \pm 0.56^{\mathrm{b}}$ & $19.24 \pm 1.70^{\mathrm{b}}$ \\
$\mathrm{CH}-\mathrm{O} 2$ & $112.3 \pm 38.3^{\mathrm{b}}$ & $8.95 \pm 1.35^{\mathrm{b}}$ & $26.66 \pm 3.69^{\mathrm{c}}$ & $20.41 \pm 1.14^{\mathrm{b}}$ \\
$\mathrm{CH}-\mathrm{O} \mathrm{3}$ & $122.7 \pm 26.1^{\mathrm{b}}$ & $8.72 \pm 0.10^{\mathrm{b}}$ & $22.23 \pm 0.02^{\mathrm{a}}$ & $20.87 \pm 0.09^{\mathrm{b}}$ \\
$\mathrm{CH}-\mathrm{O} 4$ & $136.8 \pm 48.0^{\mathrm{b}}$ & $8.71 \pm 1.09^{\mathrm{b}}$ & $23.80 \pm 0.14^{\mathrm{d}, \mathrm{e}}$ & $22.20 \pm 1.97^{\mathrm{a}}$ \\
$\mathrm{CH}-\mathrm{O} \mathrm{5}$ & $173.2 \pm 38.9^{\mathrm{b}}$ & $7.79 \pm 2.91^{\mathrm{b}}$ & $22.27 \pm 0.96^{\mathrm{a}, \mathrm{e}}$ & $16.43 \pm 1.20^{\mathrm{b}}$ \\
\hline
\end{tabular}

Values are expressed as mean \pm standard deviation. Different letters in the same column indicate significant differences $(P<0.05)$.

TABLE 5: Physical properties of chitosan films with the marjoram essential oil.

\begin{tabular}{|c|c|c|c|c|}
\hline Sample & $T(\mu \mathrm{m})$ & $\operatorname{WVP}\left(10^{-3} \mathrm{~g} / \mathrm{Pa} \cdot \mathrm{h} \cdot \mathrm{m}^{2}\right)$ & MC (\%) & $S(\%)$ \\
\hline $\mathrm{CH}$ & $49.7 \pm 7.6^{\mathrm{a}}$ & $16.51 \pm 0,96^{\mathrm{a}}$ & $20.93 \pm 0.56^{\mathrm{a}}$ & $22.25 \pm 0.31^{\mathrm{a}}$ \\
\hline CH-M 0.5 & $42.2 \pm 4.6^{\mathrm{b}}$ & $13.81 \pm 1.05^{\mathrm{a}}$ & $19.74 \pm 0.55^{\mathrm{a}}$ & $23.32 \pm 2.10^{\mathrm{a}, \mathrm{c}}$ \\
\hline CH-M 1 & $49.2 \pm 4.4^{\mathrm{ab}}$ & $13.28 \pm 1.09^{\mathrm{ac}}$ & $15.95 \pm 1.64^{\mathrm{b}}$ & $19.21 \pm 1.62^{\mathrm{b}}$ \\
\hline $\mathrm{CH}-\mathrm{M} 2$ & $51.0 \pm 7.3^{\mathrm{a}}$ & $12.85 \pm 0.55^{\mathrm{bc}}$ & $18.06 \pm 0.98^{\mathrm{a}}$ & $22.12 \pm 1.15^{\mathrm{a}, \mathrm{c}}$ \\
\hline $\mathrm{CH}-\mathrm{M} 3$ & $60.1 \pm 4.4^{\mathrm{c}}$ & $13.49 \pm 1.21^{\mathrm{bc}}$ & $21.08 \pm 1.52^{\mathrm{a}, \mathrm{c}}$ & $23.68 \pm 2.41^{\mathrm{a}, \mathrm{c}}$ \\
\hline $\mathrm{CH}-\mathrm{M} 4$ & $98.1 \pm 8.3^{\mathrm{d}}$ & $13.52 \pm 0.84^{b c}$ & $22.70 \pm 0.10^{c}$ & $24.35 \pm 0.64^{c}$ \\
\hline $\mathrm{CH}-\mathrm{M} 5$ & $133.1 \pm 2.7^{\mathrm{e}}$ & $13.67 \pm 0.82^{b c}$ & $26.42 \pm 0.65^{\mathrm{d}}$ & $23.65 \pm 0,07^{\mathrm{c}}$ \\
\hline
\end{tabular}

Values are expressed as mean \pm standard deviation. Different letters in the same column indicate significant differences $(P<0.05)$.

the initial decrease of water vapour permeability in chitosan films with cinnamon bark oil, after which the WVP values increased again as a result of the structural changes at higher essential oil concentrations. It can definitely be stated that the characteristics of all the components in the system, that is, the type of polymer, active substance and the emulsifier applied, and their mutual potential interactions, play an important role in any final properties.

The barrier properties of the marjoram samples were not affected to such an extent as the chitosan-oregano films (Table 5). The values recorded for the water vapour permeability of the modified films ranged from 12.85 to $13.81 \mathrm{~g} \cdot \mathrm{Pa}^{-1} \cdot \mathrm{h}^{-1} \cdot \mathrm{m}^{-2}$ in connection with variance in EE content. However, a decrease $(P<0.05)$ in samples with greater addition of EE (from $2 \%$ wt.) was also observed in comparison with pure chitosan film. Despite this, differences between the individual modified samples were not significant with regard to absolute values. These results correspond to the SEM analysis conducted, wherein better compatibility between the marjoram components and chitosan matrix was reported. Thus, only a mild impact on barrier properties can be presumed in comparison to samples with the oregano oil.

Moisture content (MC) provides insight into the hydrophilicity of the films. The value of $20.93 \%$ was measured for the unmodified chitosan film, which approximates data obtained by other authors [3, 27]. Following the aforementioned results for barrier function, the expectation may be for decrease in moisture content to occur in films with heightened oregano oil content. Table 4 shows that this was proven in samples containing lower EE concentrations (up to $1 \%$ wt.), although this trend was not confirmed in films with higher content of the given essential oil. When measuring particle sizes, it was evidenced that smaller particles were brought about by heightening EE concentration levels. Simultaneously, moisture content continued to rise; the values were even exceeding the control chitosan sample. Obviously, it is worth mentioning the role of the hydrophilic emulsifier utilized and its HLB value.

As can be seen in Table 5, similar results were found for the $\mathrm{CH}-\mathrm{M}$ samples; that is, $\mathrm{MC}$ content decreased in $\mathrm{CH}$ 0.5 and $\mathrm{CH}-1$, after which repeated increment in values was reported.

Film solubility in water $(S)$ is another important parameter for biopolymers, indicating the behaviour of the given film in a humid environment and reflecting the extent of biodegradability. Film solubility requirements vary according to the designated practical application. When it is used as an active edible coating intended to be consumed with the food, a high rate of water solubility is demanded. Nevertheless, low solubility in water is necessary if the polymer film functions as a secondary food packaging [16]. Herein, the control sample $(\mathrm{CH})$ exhibited a water solubility value of about $22 \%$; a similar figure has been ascertained in other works [2, 3]. As in the case of MC measurement, no general trend amongst all the samples was visible, since values decreased at lower EE concentrations and then increased again in parallel with heightened addition of the essential oil. Generally, water solubility values (\%) for both the oregano and marjoram samples equalled around 22\%, approximating the figure for unmodified chitosan $(\mathrm{CH})$. Thus, the conclusion can be drawn that chitosan plays a principal role in moisture determination, regardless of the essential oil applied. 

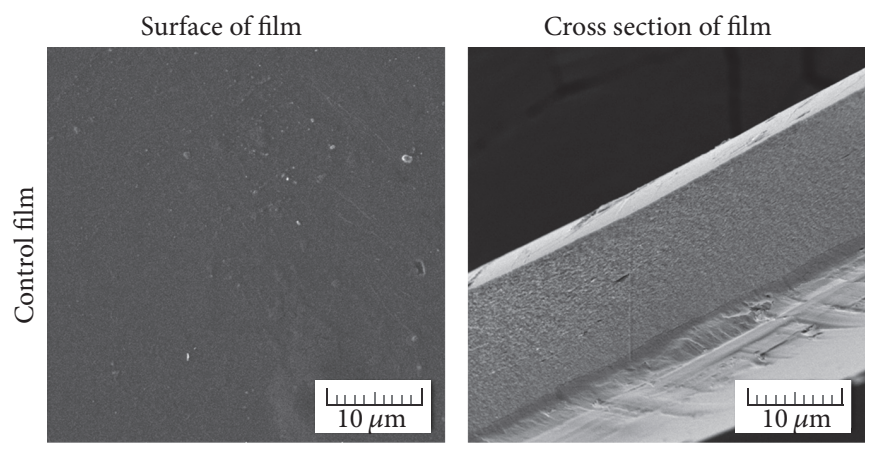

(a)
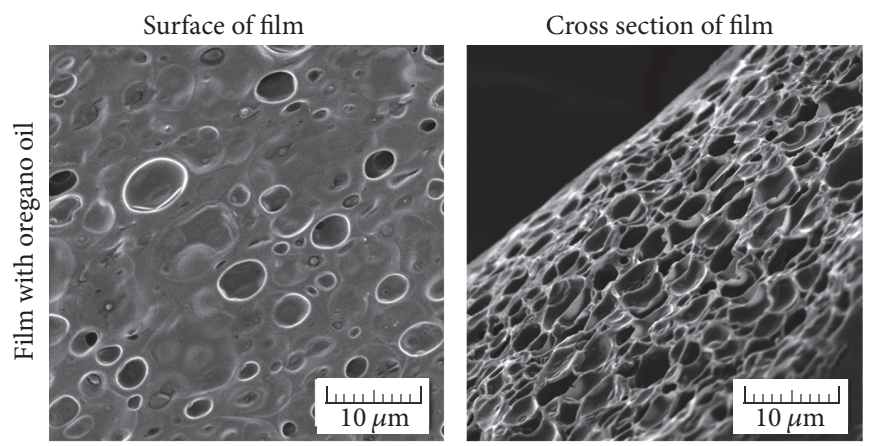

(b)
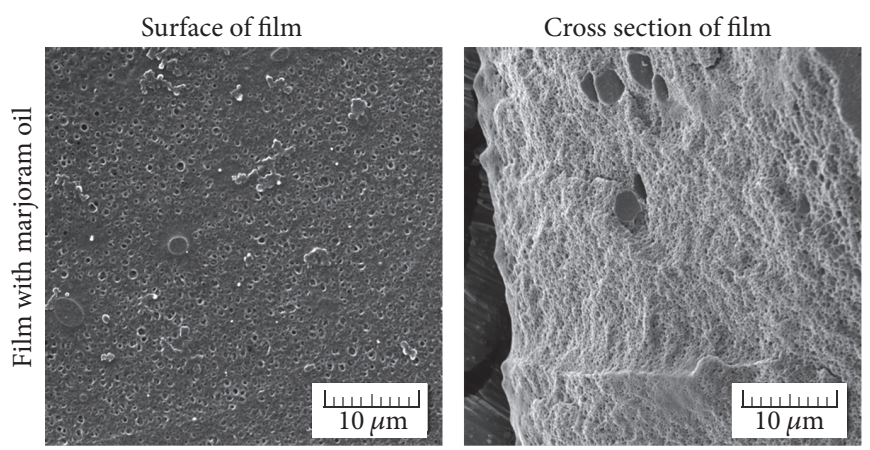

(c)

FIGURE 2: SEM micrographs of the surfaces (left) and cross sections (right) of chitosan films: (a) control, (b) with 3\% wt. oregano oil, and (c) with $3 \%$ wt. marjoram oil.

3.6. SEM Analysis. Scanning electron microscopy was applied to verify occasional structural changes in the chitosan matrix after adding the essential oils. The SEM images of surfaces and cross sections of pure chitosan film and samples with 3\% wt. of essential oil are shown in Figure 2. The control chitosan sample without any essential oil exhibited a smooth, flat surface, free of any pores or cracks (Figure 2(a)). After modifying the polymer with EE, significant microstructural changes were observed. In the case of the oregano oil, uniform distribution can be seen of relatively large ellipsoid oil droplets with an average diameter of $6 \mu \mathrm{m}$ (Figure 2(b)). Chitosan film with the marjoram essential oil demonstrated a more compact structure with smaller particles, rather spherical in shape at an average size of 1 to $2 \mu \mathrm{m}$ (Figure 2(c)).
This result can be further supported through the better compatibility manifested by the more hydrophilic terpinene4-ol in combination with marjoram and chitosan, whereas carvacrol is supposed to be more hydrophobic and hence does not allow for formation of a closer structure.

The particles in samples with both the supplemented essential oils are larger than those obtained in the filmforming solutions, a finding also revealed in a study by Torrieri et al. [25]. It is clear that the type of essential oil utilized considerably affects the final microstructure of the film. In relation to the antimicrobial tests, it can be supposed that the more compact structure of the $\mathrm{CH}-\mathrm{M}$ film restricts diffusion of the essential oil from the chitosan matrix, which is reflected in the eventual antimicrobial activity. 


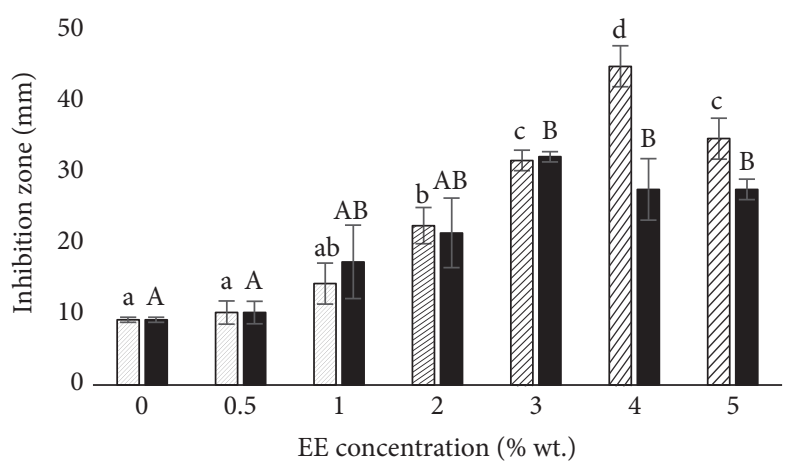

$\square 3 \mathrm{rd}$

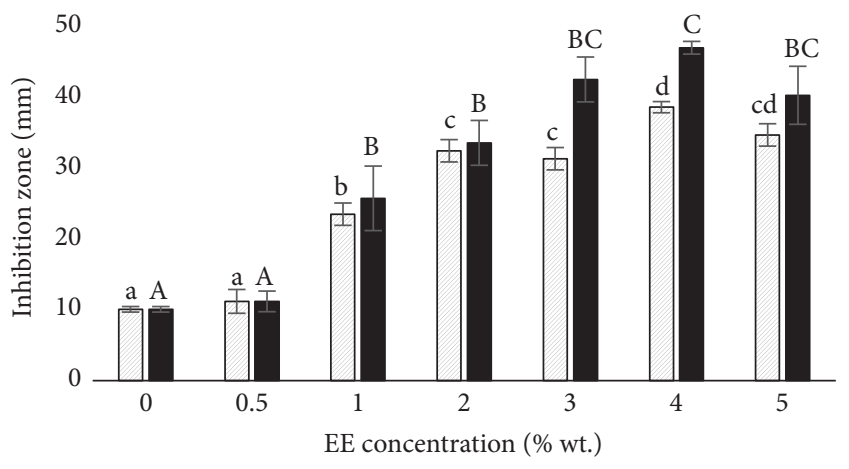

$\square 3 \mathrm{rd}$

8th

(a)

(b)

FIgURE 3: Antimicrobial activity of chitosan films with the oregano EO at days 3 and 8 against Gram-positive bacteria (a) Staphylococcus aureus and (b) Bacillus cereus. The various lowercase and uppercase letters indicate significant differences $(P<0.05)$ between the films on the 3rd and 8th day subsequent to the day they were dried, respectively.

TABLE 6: Antimicrobial activity of the oregano and marjoram essential oils against selected microorganisms.

\begin{tabular}{lcc}
\hline \multirow{2}{*}{ Microorganism } & \multicolumn{2}{c}{ Inhibition zone diameter $(\mathrm{mm})$} \\
& Oregano oil & Marjoram oil \\
\hline Staphylococcus aureus & $26.0 \pm 3.0$ & $9.0 \pm 1.0$ \\
Bacillus cereus & $18.5 \pm 1.3$ & $26.0 \pm 2.3$ \\
Salmonella typhimurium & $33.5 \pm 0.7$ & $25.5 \pm 0.7$ \\
Escherichia coli & $28.0 \pm 3.0$ & $14.0 \pm 1.0$ \\
Candida albicans & $43.0 \pm 1.0$ & $21.0 \pm 1.0$ \\
Aspergillus niger & $51.5 \pm 0.7$ & $\mathrm{x}$ \\
\hline
\end{tabular}

Values are expressed as mean \pm standard deviation; $\mathrm{x}$ : no inhibition zone.

3.7. Antimicrobial Activity. Prior to testing the chitosan films themselves, the antimicrobial activity of the pure essential oils was investigated by conducting an agar diffusion test. The results in Table 6 show the inhibition zones observed against the selected bacteria and fungi. It is clear that the activity manifested by the oregano oil was superior to that for the marjoram oil, in addition to which higher efficiency was reported against the fungal strains Candida albicans and Aspergillus niger. As regards bacteria, Gram-negative strains (E. coli, S. typhimurium) are slightly more sensitive to the investigated essential oils. Interestingly, contrasting results were obtained by Shaaban et al. [28], who tested three EOs (marjoram, clove, and cinnamon) against Gram-negative and Gram-positive strains, with the latter displaying more sensitivity to all three essential oils.

Further evaluation involved carrying out an agar diffusion test to investigate the antimicrobial activity of the essential oils incorporated in the chitosan films, that is, any clear inhibition zones around the samples were measured, these having been caused by diffusion of the active substances through the medium. Chitosan is renowned for its antimicrobial properties, believed to depend on the positive surface charge of protonated $\mathrm{NH}_{3}{ }^{+}$groups, these being capable of interfering with negatively charged bacterial cell surfaces [8, 29]. In this work, pure chitosan film, completely absent of an EO, was applied as a control to check for antimicrobial activity. However, no inhibitory effect was noticed. The explanation for this could be that the antimicrobial activity of chitosan is limited when it is fixed in the form of a polymer film. Indeed, a similar result was obtained by Wang et al. [2], who investigated chitosan films with clove bud, cinnamon, and star anise essential oils. Figures 3-5 display results obtained with the chitosan-oregano films against selected bacteria and fungi after 3 and 8 days had passed since drying the film. All the samples exhibited antibacterial and antifungal activity even at lower EE concentrations. Significant increase $(P<0.05)$ in the measured inhibition zones was discerned despite the presence of only approximately $1 \% \mathrm{wt}$. concentration of oregano: Tween 80 in most of the bacterial strains (Figures 3 and 4). In most cases, the diameters of the inhibition zones expanded proportionally in parallel with increase in EE content, with the exception of the highest concentration ( $5 \% \mathrm{wt}$.), when a moderate descent in values was observed. The greatest resistance was demonstrated by Aspergillus niger, when 3\% wt. of EO : Tween 80 was necessary to record significant activity (Figure 5(b)). After repeating the agar diffusion test (on the 8th day after drying the films), continuation of such antimicrobial activity was confirmed. Although the lesser inhibition zones were measured for the majority of samples, occasionally activity was seen to be comparable or even higher (see Figure 5, CH-O 3 to $\mathrm{CH}$ $\mathrm{O} 5$ ). Based on this finding, further testing is intended on chitosan-oregano films destined for a system with prolonged active substance release.

However, samples containing the marjoram essential oil presented only minor antibacterial activity, when a small inhibition zone was present at the highest EE concentrations (data not shown). In terms of the fungi (Candida albicans, Aspergillus niger), extensive microbial growth over the round 


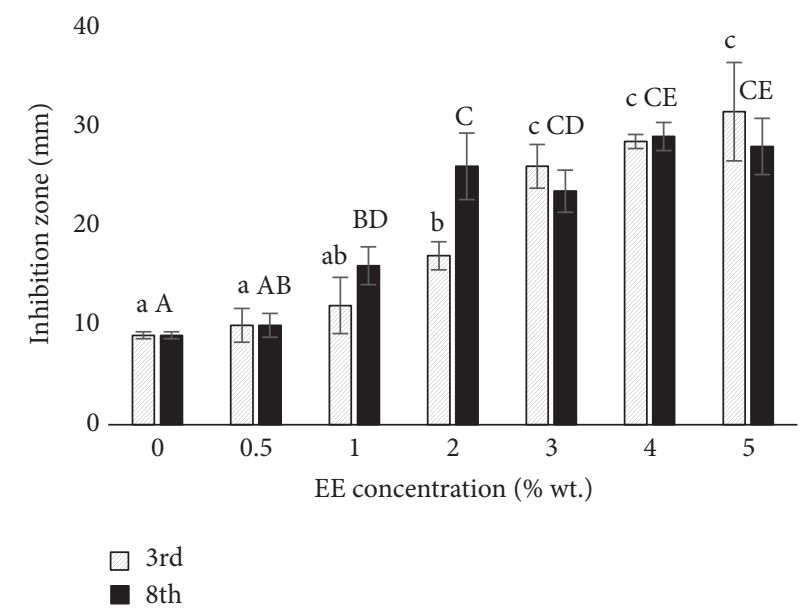

(a)

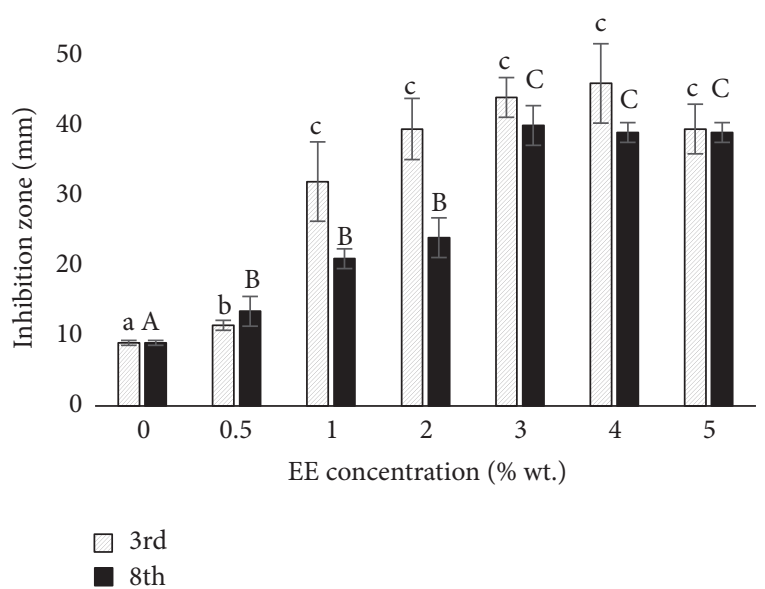

(b)

Figure 4: Antimicrobial activity of chitosan films with the oregano EO at days 3 and 8 against Gram-negative bacteria (a) Escherichia coli and (b) Salmonella typhimurium. The various lowercase and uppercase letters indicate significant differences $(P<0.05)$ between the films on the 3rd and 8th day subsequent to the day they were dried, respectively.

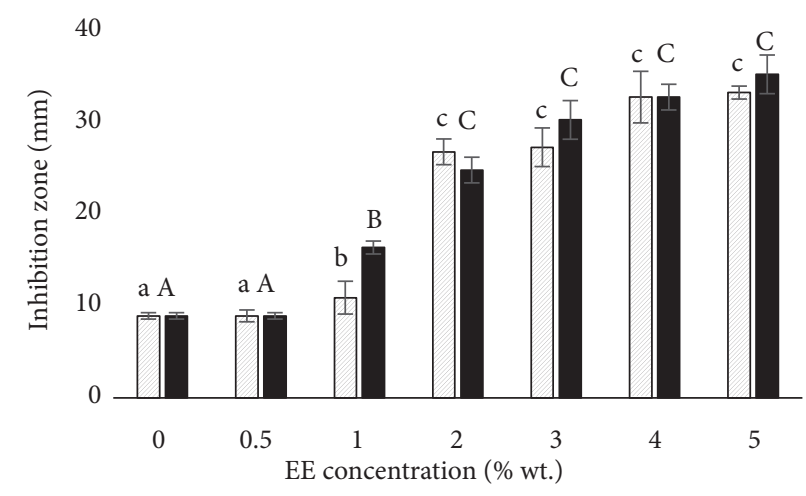

$\square 3 \mathrm{rd}$

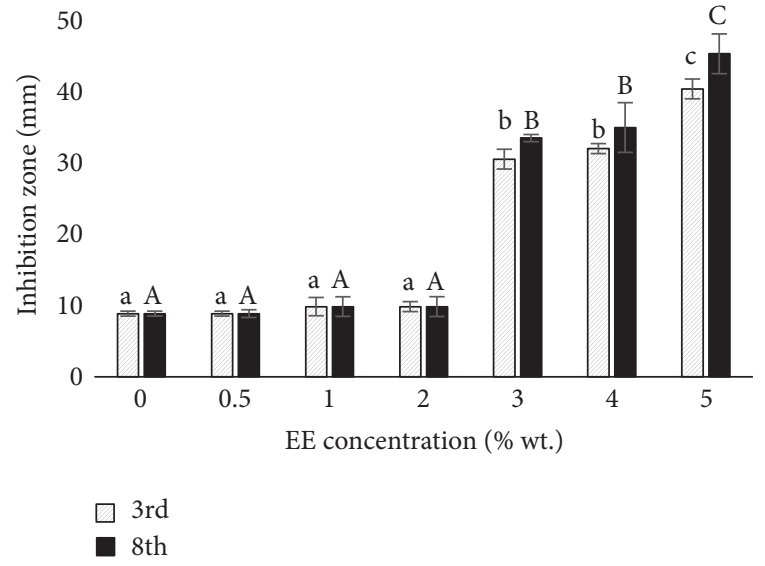

(b)

FIGURE 5: Antimicrobial activity of chitosan films with the oregano EO at days 3 and 8 against fungi (a) Candida albicans and (b) Aspergillus niger. The various lowercase and uppercase letters indicate significant differences $(P<0.05)$ between the films on the 3rd and 8th day subsequent to the day they were dried, respectively.

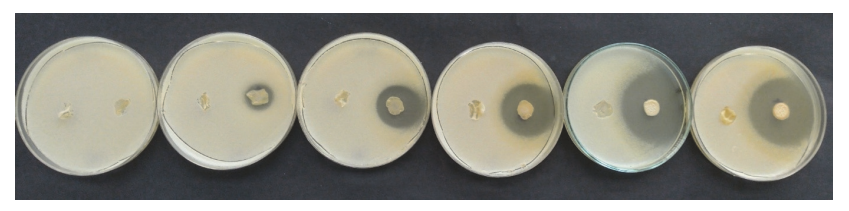

FIGURE 6: Inhibition zones of chitosan films with $0.5,1,2,3,4$, and $5 \%$ wt. of the marjoram (left) and oregano (right) oils on Candida albicans.

samples was visible, indicating the significant resistance of these strains to the chitosan-marjoram oil system.

Figures 6 and 7 detail the results from samples containing the oregano and/or marjoram essential oils against the fungal strains. The differences in antifungal activity exhibited by the given essential oils are obvious.

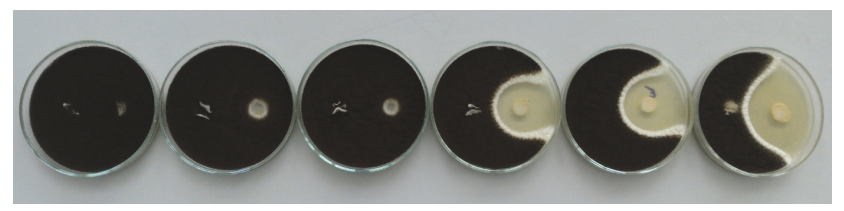

FIgURE 7: Inhibition zones of chitosan films with $0.5,1,2,3$, 4, and $5 \%$ wt. of the marjoram (left) and oregano (right) oils on Aspergillus niger.

The results herein reveal the great extent of antimicrobial activity demonstrated by the oregano EO, which is in accordance with other studies. Zivanovic et al. [8] investigated the antimicrobial effects of medium-molecular-weight chitosan films supplemented with the essential oils of anise, basil, coriander, and oregano, the latter exhibiting the highest 
intensity of antimicrobial activity. Indeed, the antimicrobial properties of oregano oil strongly depend on the concentration of the main active substances present, that is, carvacrol and thymol. The content of these varies, depending on the origin, harvesting period, processing, and storage conditions of the EO. The principle underlying such antimicrobial action consists of attack by these phenolic active substances on cell membranes, leading to increased permeability and cytoplasm leakage. The considerable antimicrobial activity of both components was also ascertained by Gallucci et al. [11], who investigated the effects of nine monoterpenes and their combinations. Therein, carvacrol and thymol exerted the strongest effect, which, in comparison with other tested substances, ascertained how significant the presence and the relative position of the hydroxyl group were, as well as the importance of the aromatic ring to said antimicrobial activity. The structure of the compounds comprised within the essential oils is strongly associated with water solubility and capacity for hydrogen bonding, these properties influencing any consequent antimicrobial activity. The work by Gallucci et al. [11] revealed that although carvacrol, thymol, and eugenol are known to be effective antimicrobial components, the latter under circumstances of high water solubility exhibited reduced inhibitory action. Herein, according to the GC-MS results, the main constituents of the oregano and marjoram oils utilized in the study were carvacrol and terpinene-4-ol, respectively. Elsewhere, in research conducted by Griffin et al. [30], the solubility in water of these compounds was determined as $830 \mathrm{ppm}$ for carvacrol and $1491 \mathrm{ppm}$ for terpinene4-ol. Based on microbiological testing of the samples in the present study, the conclusion can be drawn that the carvacrol in the oregano oil (with lower aqueous solubility) exhibited significantly greater antimicrobial effects than the marjoram oil, thereby confirming the above-mentioned data from other authors.

\section{Conclusion}

Chitosan was modified with two essential oils of the Origanum species (oregano and marjoram) to compare their effects on the resultant behaviour of film-forming solutions and polymer films. GC-MS analysis proved that the oregano oil was rich in the phenolic compound carvacrol, whereas the marjoram sample predominantly comprised the alcohols terpinene-4-ol and sabinene hydrate. Variation in the structural properties of the active substances in both EOs meant that significant differentiation was revealed in the characteristics of the film-forming solutions, as well as in the physical, antimicrobial, and morphological features of the prepared chitosan films. The crucial role of Tween 80 nonionic emulsifier was also demonstrated. In the oregano samples, large oil droplets were evidenced in the films by dynamic light scattering and SEM analysis, while considerable antimicrobial efficiency was also manifested against bacterial and fungal strains. Moreover, supplementing the biopolymer with oregano enhanced the barrier properties of such films. Based on antimicrobial tests and evaluation of physical and visual parameters, EE concentrations at 2 to $3 \% \mathrm{wt}$. were discerned as being optimum. The marjoram-based samples were found to possess a more compact structure, most likely causing a limited antimicrobial activity against the microorganisms tested. Therefore, these findings confirm that the combination of oregano EO and Tween 80 emulsifier would be appropriate in a chitosan system, potentially serving as active food packaging with wide-ranging antimicrobial efficacy.

\section{Conflicts of Interest}

The authors declare that they have no conflicts of interest.

\section{References}

[1] M. Rinaudo, "Chitin and chitosan: properties and applications," Progress in Polymer Science, vol. 31, no. 7, pp. 603-632, 2006.

[2] L. Wang, F. Liu, Y. Jiang et al., "Synergistic antimicrobial activities of natural essential oils with chitosan films," Journal of Agricultural and Food Chemistry, vol. 59, no. 23, pp. 12411-12419, 2011.

[3] Y. Peng, L. Yin, and Y. Li, "Combined effects of lemon essential oil and surfactants on physical and structural properties of chitosan films," International Journal of Food Science \& Technology, vol. 48, no. 1, pp. 44-50, 2013.

[4] P. López, C. Sánchez, R. Batlle, and C. Nerín, "Development of flexible antimicrobial films using essential oils as active agents," Journal of Agricultural and Food Chemistry, vol. 55, no. 21, pp. 8814-8824, 2007.

[5] K. C. Huber and M. E. Embuscado, Edible Films and Coatings for Food Applications, Springer Science+Business Medi LLC, New York, NY, USA, 2009.

[6] W. Du, R. J. Avena-Bustillos, S. S. T. Hua, and T. H. McHugh, "Antimicrobial volatile essential oils in edible films for food safety," Science against Microbial Pathogens: Communicating Current Research and Technological Advances, pp. 1124-1134, 2011.

[7] M. H. Hosseini, S. H. Razavi, and M. A. Mousavi, "Antimicrobial, physical and mechanical properties of chitosan-based films incorporated with thyme, clove and cinnamon essential oils," Journal of Food Processing and Preservation, vol. 33, no. 6, pp. 727-743, 2009.

[8] S. Zivanovic, S. Chi, and A. F. Draughon, "Antimicrobial activity of chitosan films enriched with essential oils," Journal of Food Science, vol. 70, no. 1, pp. M45-M51, 2005.

[9] U. Siripatrawan and S. Noipha, "Active film from chitosan incorporating green tea extract for shelf life extension of pork sausages," Food Hydrocolloids, vol. 27, no. 1, pp. 102-108, 2012.

[10] Y. Pranoto, S. K. Rakshit, and V. M. Salokhe, "Enhancing antimicrobial activity of chitosan films by incorporating garlic oil, potassium sorbate and nisin," LWT-Food Science and Technology, vol. 38, no. 8, pp. 859-865, 2005.

[11] M. N. Gallucci, M. Oliva, C. Casero et al., "Antimicrobial combined action of terpenes against the food-borne microorganisms Escherichia coli, Staphylococcus aureus and Bacillus cereus," Flavour and Fragrance Journal, vol. 24, no. 6, pp. 348354, 2009.

[12] A. Dashipour, R. Khaksar, H. Hosseini, S. Shojaee-Aliabadi, and K. Ghanati, "Physical, antioxidant and antimicrobial characteristics of carboxymethyl cellulose edible film cooperated with clove essential oil," Zahedan Journal of Research in Medical Sciences, vol. 16, pp. 34-42, 2014. 
[13] M. Z. Elsabee and E. S. Abdou, "Chitosan based edible films and coatings: a review," Materials Science and Engineering C, vol. 33, no. 4, pp. 1819-1841, 2013.

[14] L. Keawchaoon and R. Yoksan, "Preparation, characterization and in vitro release study of carvacrol-loaded chitosan nanoparticles," Colloids and Surfaces B: Biointerfaces, vol. 84, no. 1, pp. 163-171, 2011.

[15] M. A. López-Mata, S. Ruiz-Cruz, N. P. Silva-Beltrán, J. D. J. Ornelas-Paz, P. B. Zamudio-Flores, and S. E. Burruel-Ibarra, "Physicochemical, antimicrobial and antioxidant properties of chitosan films incorporated with carvacrol," Molecules, vol. 18, no. 11, pp. 13735-13753, 2013.

[16] J. F. Rubilar, R. M. S. Cruz, H. D. Silva, A. A. Vicente, I. Khmelinskii, and M. C. Vieira, "Physico-mechanical properties of chitosan films with carvacrol and grape seed extract," Journal of Food Engineering, vol. 115, no. 4, pp. 466-474, 2013.

[17] M. Abdollahi, M. Rezaei, and G. Farzi, "Improvement of active chitosan film properties with rosemary essential oil for food packaging," International Journal of Food Science and Technology, vol. 47, no. 4, pp. 847-853, 2012.

[18] T. Mehdizadeh, H. Tajik, S. M. R. Rohani, and A. R. Oromiehie, "Antibacterial, antioxidant and optical properties of edible starch-chitosan composite film containing thymus kotschyanus essential oil," Veterinary Research Forum, vol. 3, pp. 167-173, 2012.

[19] Á. Perdones, A. Chiralt, and M. Vargas, "Properties of filmforming dispersions and films based on chitosan containing basil and thyme essential oil," Food Hydrocolloids, vol. 57, pp. 271-279, 2016.

[20] ASTM, "Standard Test Methods for Water Vapor Transmission of Materials", Tech. Rep., 1995.

[21] D. J. Daferera, B. N. Ziogas, and M. G. Polissiou, "GC-MS analysis of essential oils from some Greek aromatic plants and their fungitoxicity on Penicillium digitatum," Journal of Agricultural and Food Chemistry, vol. 48, no. 6, pp. 2576-2581, 2000.

[22] J. Bonilla, L. Atarés, M. Vargas, and A. Chiralt, "Effect of basil and thyme essential oils and homogenization conditions on properties of chitosan based films," Food Hydrocolloids, vol. 26, pp. 9-16, 2012.

[23] M. J. Fabra, M. L. Flores-López, M. A. Cerqueira, D. J. de Rodriguez, J. M. Lagaron, and A. A. Vicente, "Layer-by-Layer Technique to Developing Functional Nanolaminate Films with Antifungal Activity," Food and Bioprocess Technology, vol. 9, no. 3, pp. 471-480, 2016.

[24] E. A. Elhefian, E. Elgannodi, A. Mainal, and Y. AH, "Characterization of chitosan in acetic acid: rheological and thermal studies," Turkish Journal of Chemistry, vol. 34, pp. 47-56, 2010.

[25] E. Torrieri, S. Cavella, and P. Masi, "Effect of rosemary oil and an emulsion of essential oils on structure and physical properties of chitosan film," Chemical Engineering Transactions, vol. 43, pp. 25-30, 2016.

[26] M. A. López-Mata, S. Ruiz-Cruz, N. P. Silva-Beltrán et al., "Physicochemical and Antioxidant Properties of Chitosan Films Incorporated with Cinnamon Oil," International Journal of Polymer Science, vol. 2015, Article ID 974506, 2015.

[27] Y. Peng and Y. Li, "Combined effects of two kinds of essential oils on physical, mechanical and structural properties of chitosan films," Food Hydrocolloids, vol. 36, pp. 287-293, 2014.

[28] H. A. Shaaban, H. S. Ali, G. F. Bareh, A. R. S. Al-khalifa, and M. M. Amer, "Antimicrobial activity of two polysaccharide edible films incorporated with essential oils against three pathogenic bacteria," Journal of Applied Sciences, vol. 17, no. 4, pp. 171-183, 2017.

[29] V. Coma, A. Martial-Gros, S. Garreau, A. Copinet, F. Salin, and A. Deschamps, "Edible antimicrobial films based on chitosan matrix," Journal of Food Science, vol. 67, no. 3, pp. 1162-1169, 2002.

[30] S. G. Griffin, S. G. Wyllie, J. L. Markham, and D. N. Leach, "The role of structure and molecular properties of terpenoids in determining their antimicrobial activity," Flavour and Fragrance Journal, vol. 14, pp. 332-332, 1999. 

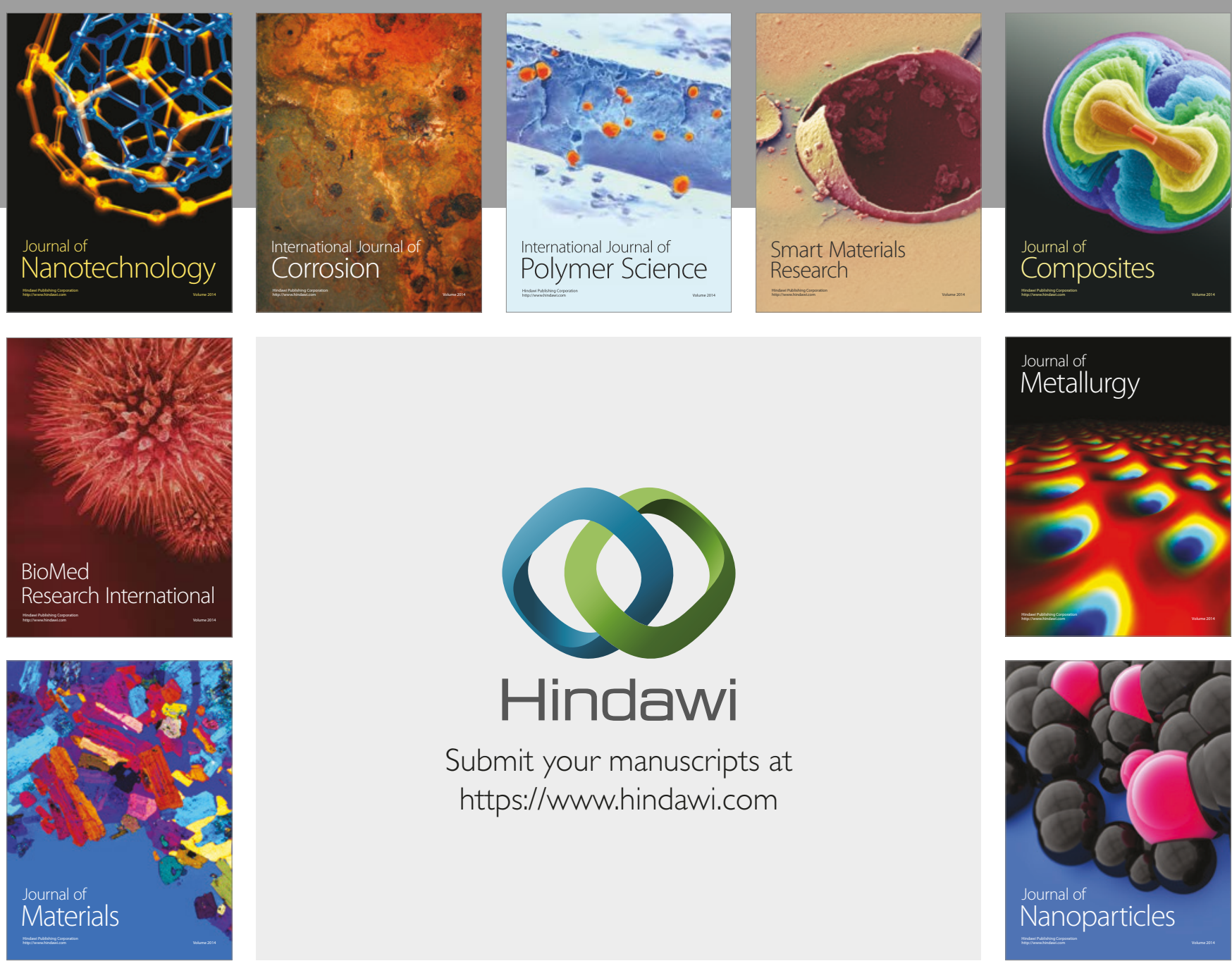

\section{Hindawi}

Submit your manuscripts at

https://www.hindawi.com
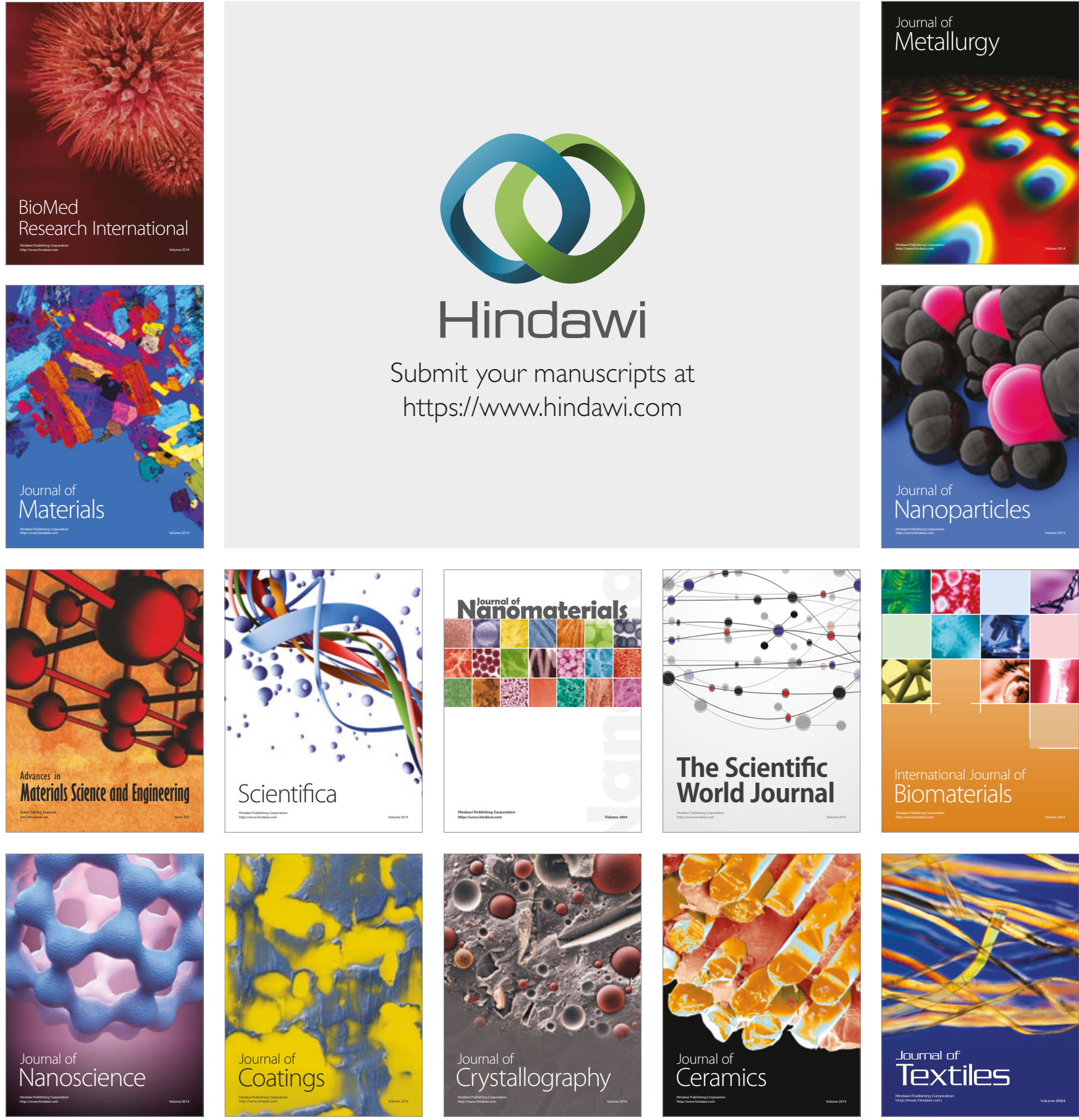

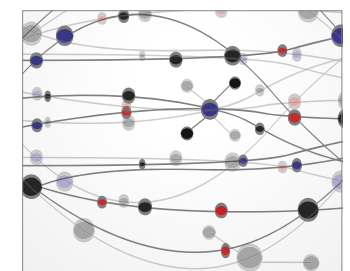

The Scientific World Journal
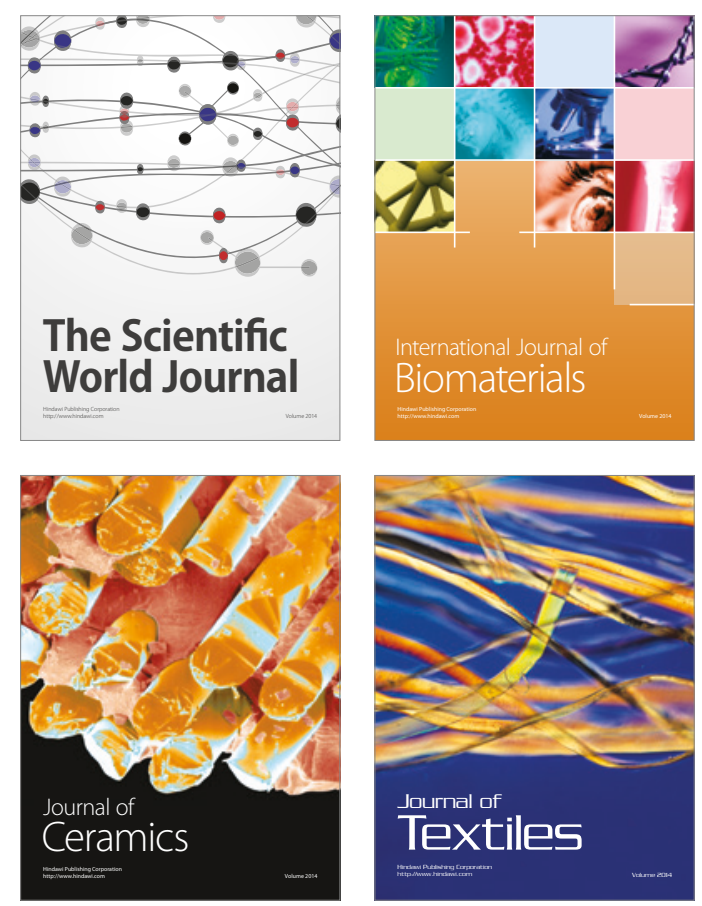